\title{
Molecular characterization of methicillin-resistant Staphylococcus aureus isolates from a hospital in Ghana
}

\author{
*1, ${ }^{2}$ Asante, J., ${ }^{1}$ Govinden, U., ${ }^{2}$ Owusu-Ofori, A., ${ }^{3}$ Bester, L. A., and ${ }^{1}$ Essack, S. Y. \\ ${ }^{1}$ Antimicrobial Research Unit, College of Health Sciences, University of KwaZulu Natal, Private Bag \\ X54001, Durban, 4000, South Africa \\ ${ }^{2}$ Department of Clinical Microbiology, School of Medical Sciences, Kwame Nkrumah University of \\ Science and Technology, Kumasi, Ghana \\ ${ }^{3}$ Biomedical Resource Unit, School of Laboratory Medicine and Medical Sciences, University of KwaZulu \\ Natal, Durban, South Africa \\ *Correspondence to: josante33@yahoo.com
}

\begin{abstract}
:
Background: Methicillin-resistant Staphylococcus aureus (MRSA) are a major cause of hospital- and community-acquired infection. They can colonize humans and cause a wide range of infections including pneumonia, endocarditis and bacteraemia. We investigated the molecular mechanism of resistance and virulence of MRSA isolates from a teaching hospital in Ghana.

Methodology: A total of $91 \mathrm{~S}$. aureus isolates constituted the initial bacterial sample. Identification of $S$. aureus was confirmed by the VITEK 2 system. The cefoxitin screen test was used to detect MRSA and antibiotic susceptibility was determined using the VITEK 2 system. The resistance (mecA, blaZ, aac-aph, ermC, and tetK) and virulence (IukS/F-PV, hla, hld and eta) genes were amplified by polymerase chain reaction (PCR) and positive samples subjected to DNA sequencing. Pulsed field gel electrophoresis (PFGE) was used to ascertain the relatedness of the isolates.

Results: Fifty-eight of $91(63.7 \%)$ isolates were putatively methicillin resistant by the phenotypic cefoxitin screen test and oxacillin MICs. However, $43(47 \%)$ of the isolates were genotypically confirmed as MRSA based on PCR detection of the mecA gene. Furthermore, $37.9 \%$ of isolates displayed resistance to tetracycline, $19 \%$ to trimethoprim-sulphamethoxazole, $15.5 \%$ to clindamycin, $12.1 \%$ to gentamicin, $13.8 \%$ to ciprofloxacin and erythromycin, $6.9 \%$ to moxifloxacin and $7.0 \%$ to rifampicin. None of the isolates was positive for inducible clindamycin resistance. The prevalence of resistance (mecA, blaZ, aac $\left(6^{\prime}\right)-a p h\left(2^{\prime \prime}\right)$, tetK, and ermC) and virulence (hla and lukS/F-PV) genes respectively were $74 \%, 33 \%, 22 \%, 19 \%, 3 \%, 5 \%$ and $3 \%$, with isolates organized in two highly related clades.

Conclusion: Results indicate a fairly high occurrence of MRSA, which can complicate the effective therapy of $S$. aureus infections, necessitating surveillance and stringent infection control programmes to forestall its spread.
\end{abstract}

Keywords: MRSA, mecA, blaZ, hla, lukS/F-PV

Received February 18, 2019; Revised April 9, 2019; Accepted April 11, 2019

Copyright 2019 AJCEM Open Access. This article is licensed and distributed under the terms of the Creative Commons Attrition 4.0 International License (http://creativecommmons.org/licenses/by/4.0), which permits unrestricted use, distribution and reproduction in any medium, provided credit is given to the original author(s) and the source. 


\title{
Caractérisation moléculaire d'isolats de Staphylococcus aureus résistants à la méthicilline provenant d'un hôpital du Ghana
}

\author{
${ }^{* 1,2}$ Asante, J., ${ }^{1}$ Govinden, U., ${ }^{2}$ Owusu-Ofori, A., ${ }^{3}$ Bester, L. A., and ${ }^{1}$ Essack, S. Y. \\ ${ }^{1}$ Unité de recherche antimicrobienne, Collège des sciences de la santé, Université du KwaZulu Natal, \\ Sac privé X54001, Durban, 4000, Afrique du Sud. \\ ${ }^{2}$ Département de microbiologie clinique, Faculté des sciences médicales, Université des sciences et \\ technologies Kwame Nkrumah, Kumasi, Ghana \\ ${ }^{3}$ Unité des ressources biomédicales, École de médecine de laboratoire et des sciences médicales, \\ Université de KwaZulu Natal, Durban, Afrique du Sud \\ *Correspondance à: josante33@yahoo.com
}

\begin{abstract}
Abstrait:
Contexte: Le Staphylococcus aureus résistant à la méthicilline (SARM) est une cause majeure d'infection acquise à l'hôpital et dans la communauté. Ils peuvent coloniser les humains et causer un large éventail d'infections, notamment la pneumonie, l'endocardite et la bactériémie. Nous avons étudié le mécanisme moléculaire de résistance et de virulence des isolats de SARM provenant d'un hôpital universitaire au Ghana.

Méthodologie: Au total, 91 isolats de S. aureus constituaient l'échantillon bactérien initial. L'identification de $\mathrm{S}$. aureus a été confirmée par le système VITEK 2 . Le test de dépistage à la céfoxitine a été utilisé pour détecter le SARM et la sensibilité aux antibiotiques a été déterminée à l'aide du système VITEK 2. Les gènes de résistance ( $m e c A, b l a Z, a a c-a p h$, ermC et tetK) et de virulence (lukS/F-PV, hla, hld et eta) ont été amplifiés par une réaction en chaîne de la polymérase $(P C R)$ et des échantillons positifs soumis à un séquençage de I'ADN. Une électrophorèse sur gel en champ pulsé (PFGE) a été utilisée pour déterminer le caractère apparent des isolats.

Résultats: Cinquante-huit des 91 isolats $(63,7 \%)$ étaient présumés résistants à la méthicilline par le test de dépistage phénotypique à la céfoxitine et par les CMI oxacillines. Cependant, $43(47 \%)$ des isolats ont été confirmés génotypiquement comme SARM sur la base de la détection par PCR du gène $m e c A$. En outre, $37,9 \%$ des isolats présentaient une résistance à la tétracycline, $19 \%$ au triméthoprime-sulfaméthoxazole, $15,5 \%$ à la clindamycine, $12,1 \%$ à la gentamicine, $13,8 \%$ à la ciprofloxacine et à l'érythromycine, $6,9 \%$ à la moxifloxacine et $7,0 \%$ à la rifampicine. Aucun des isolats n'était positif pour la résistance inductible à la clindamycine. La prévalence des gènes de résistance ( $m e c A, b l a Z, a a c\left(6^{\prime}\right)-a p h\left(2^{\prime \prime}\right)$, tetK et ermC) et de virulence (hla et lukS/F-PV) était respectivement de $74 \%, 33 \%, 22 \%, 19 \%, 3 \%, 5 \%$ et $3 \%$, avec des isolats organisés en deux clades fortement apparentés.

Conclusion: Les résultats indiquent une présence assez élevée de SARM, ce qui peut compliquer le traitement efficace des infections à $S$. aureus, nécessitant une surveillance et des programmes de contrôle des infections rigoureux pour prévenir sa propagation.
\end{abstract}

Mots-clés: SARM, mecA, blaZ, hla, lukS/F-PV

\section{Introduction:}

Staphylococcus aureus cause a variety of infections, including mild skin infections such as boils, stye and furuncles as well as more severe infections such as meningitis, pneumonia, phlebitis, mastitis, urinary tract infections, endocarditis and osteomyelitis (1). Methicillin resistance is problematic for many healthcare facilities worldwide as is the occurrence of community strains of methicillin resistant Staphylococcus aureus (MRSA) which also harbor genes associated with increased virulence $(2,3)$. MRSA strains are produced by $S$. aureus when the mecA gene is acquired by methicillin susceptible $S$. aureus (MSSA). The mecA gene is borne on the mobile element referred to as the staphylococcal cassette chromosome (SCC) mec $(4,5)$.

There is considerable variability in the prevalence as well as the epidemiology of MRSA within and between countries (6) with limited data on the antibiotic susceptibility patterns and 
molecular epidemiology of MRSA in Africa. Several African countries report a MRSA prevalence ranging from $4.8 \%$ to $20.0 \%$ (7-14). This study investigated the antibiotic susceptibility and molecular characterization of MRSA isolates from clinical samples in a Ghanaian hospital.

\section{Materials and methods:}

\section{Ethical considerations}

Ethical clearance was obtained from Biomedical Research Ethics Committee of University of KwaZulu-Natal (BE068/15) and the Committee on Human Research, Publication and Ethics of the Kwame Nkrumah University of Science and Technology, Kumasi, Ghana (CHRPE/AP/220/15).

\section{Collection and identification of bacterial isolates}

A total of $91 \mathrm{~S}$. aureus isolates from different patients were collected from the Komfo Anokye Teaching Hospital in Ghana between May and September 2015. Presumptive staphylococci were identified by colony morphology (cream to golden yellow colour) on blood agar and the coagulase test (slide method) conducted by the Microbiology Unit of the hospital. Isolates were subjected to further tests including mannitol fermentation and the tube coagulase test. The identity of isolates was also confirmed by the automated VITEK 2 system (BioMérieux, Marcy-L'Etoile, France). Fifty-eight isolates were confirmed as MRSA (the cefoxitin screen test) and included for further study.

\section{Detection of MRSA and antibiotic susceptibility profiles}

The cefoxitin test was used to screen for MRSA according to CLSI guidelines (15). The MICs for MRSA isolates were determined using the automated VITEK 2 system for the following antibiotics: oxacillin, gentamicin, ciprofloxacin, moxifloxacin, erythromycin, clindamycin, linezolid, teicoplanin, vancomycin, tetracycline, tigecycline, fusidic acid, rifampicin and trimethoprimsulfamethoxazole, and results interpreted according to CLSI guidelines (15). S. aureus ATCC 25923 was used as the reference strain. Inducible clindamycin resistance was tested by the 'D-zone' (16).

DNA extraction, PCR and sequencing of virulence and resistance genes

Genomic DNA was extracted using the Roche High Pure PCR Template Preparation Kit (Roche, Mannheim, Germany) according to the manufacturer's instructions and the concentration and purity were determined by Nanodrop ${ }^{\mathrm{TM}}$ 1000 spectrophotometer (Thermo Scientific, USA). The resistance genes mecA, blaz, aac-aph, ermc, tetK conferring resistance to oxacillin, penicillin, aminoglycosides, macrolidelincosamide-streptogramin B and tetracyclines respectively and the virulence genes lukS/F-PV, hla, hld and eta encoding Panton-Valentine Leucocidin $(P V L)$, alpha haemolysin, delta haemolysin and exfoliative toxin $A$ respectively were amplified. Amplification of genes was done using $\mathrm{T}_{100} \mathrm{TM}$ Thermal cycler (Bio-Rad, USA), using primers described elsewhere (17-20) (Table 1).

Genes investigated are those that confer resistance to some of the most commonly prescribed antibiotics in Ghana and virulence genes were selected based on their importance in staphylococcal infections. PCR experiments were carried out using the $2 x$ PCR master mix (ThermoScientific, USA), $1.25 \mu \mathrm{L}$ each of forward and reverse primers, and 50-200 ng of template DNA in a total reaction volume of $25 \mu \mathrm{L}$. PCR products were run on $1.5 \%$ agarose gel at $65 \mathrm{~V}$ for $90 \mathrm{~min}$ and visualized by UV transillumination using Bio-Rad ChemiDoc ${ }^{\mathrm{TM}}$ MP System (Bio-Rad, UK). The PCR products were sequenced (Inqaba Biotech, Pretoria, South Africa) to confirm the identity of the genes. Analysis of the sequences was done using ChromasPro 1.9.9.1 (Technelysium, Queensland Australia), BioEdit and BLAST 2.0 available on the National Center for Biotechnology Information (NCBI) website http://www.ncbi.nhlm.nih.gov/blast/BLAST.cgi. 
Table 1: Oligonucleotide primers and cycling conditions for the detection of genes in this study

\begin{tabular}{|c|c|c|c|c|}
\hline Gene & Primer sequence & PCR program & $\begin{array}{l}\text { Amplicon } \\
\text { size (bp) }\end{array}$ & Reference \\
\hline \multirow[t]{2}{*}{ mecA } & F-AACAGGTGAATTATTAGCACTTGTAAG & $3 \min 95^{\circ} \mathrm{C}, 30 \mathrm{~s} 55^{\circ} \mathrm{C}, 1 \mathrm{~min} 72^{\circ} \mathrm{C}$ & 174 & Ref 17 \\
\hline & R-ATTGCTGTTAATATTTTTTGAGTTGAA & & & \\
\hline \multirow[t]{2}{*}{ blaZ } & F-ACTTCAACACCTGCTGCTTTC & $3 \min 95^{\circ} \mathrm{C}, 30 \mathrm{~s} 55^{\circ} \mathrm{C}, 1 \mathrm{~min} 72^{\circ} \mathrm{C}$ & 173 & Ref 17 \\
\hline & R-TGACCACTTITATCAGCAACC & & & \\
\hline \multirow[t]{2}{*}{ tetK } & F-TCGATAGGAACAGCAGTA & $3 \min 95^{\circ} \mathrm{C}, 30 \mathrm{~s} 51^{\circ} \mathrm{C}, 1 \mathrm{~min} 72^{\circ} \mathrm{C}$ & 169 & Ref 18 \\
\hline & R-CAGCAGATCCTACTCCTT & & & \\
\hline \multirow{2}{*}{$\begin{array}{l}\text { aac }\left(6^{\prime}\right)- \\
\text { aph }\left(2^{\prime \prime}\right)\end{array}$} & F-TAATCCAAGAGCAATAAGGGC & $3 \min 95^{\circ} \mathrm{C}, 30 \mathrm{~s} 54^{\circ} \mathrm{C}, 1 \mathrm{~min} 72^{\circ} \mathrm{C}$ & 227 & Ref 19 \\
\hline & R-GCCACACTATCATAACCACTA & & & \\
\hline \multirow[t]{2}{*}{ ermC } & F-CTTGTTGATCACGATAATTTCC & $3 \min 95^{\circ} \mathrm{C}, 30 \mathrm{~s} 52^{\circ} \mathrm{C}, 1 \mathrm{~min} 72^{\circ} \mathrm{C}$ & 190 & Ref 17 \\
\hline & R-ATCTTTTAGCAAACCCGTATTC & & & \\
\hline \multirow[t]{2}{*}{ eta } & F-GCAGGTGTTGATTTAGCATT & $3 \min 95^{\circ} \mathrm{C}, 30 \mathrm{~s} 51^{\circ} \mathrm{C}, 1 \mathrm{~min} 72^{\circ} \mathrm{C}$ & 93 & Ref 20 \\
\hline & R-AGATGTCCCTATTTTTGCTG & & & \\
\hline \multirow[t]{2}{*}{ IUKS/F-PV } & F-ATCATTAGGTAAAATGTCTGGACATGATCCA & $3 \min 95^{\circ} \mathrm{C}, 30 \mathrm{~s} 58^{\circ} \mathrm{C}, 1 \mathrm{~min} 72^{\circ} \mathrm{C}$ & 443 & Ref 20 \\
\hline & R-GCATCAAGTGTATTGGATAGCAAAAGC & & & \\
\hline \multirow[t]{2}{*}{ hla } & F-CTGATTACTATCCAAGAAATTCGATTG & $3 \min 95^{\circ} \mathrm{C}, 30 \mathrm{~s} 55^{\circ} \mathrm{C}, 1 \mathrm{~min} 72^{\circ} \mathrm{C}$ & 209 & Ref 20 \\
\hline & R-CTTTCCAGCCTACTTITITATCAGT & & & \\
\hline \multirow[t]{2}{*}{ hld } & F-AAGAATTTTTATCTTAATTAAGGAAGGAGTG & $3 \min 95^{\circ} \mathrm{C}, 30 \mathrm{~s} 55^{\circ} \mathrm{C}, 1 \mathrm{~min} 72^{\circ} \mathrm{C}$ & 111 & Ref 20 \\
\hline & R-TTAGTGAATTTGTTCACTGTGTCGA & & & \\
\hline
\end{tabular}

\section{PFGE typing}

Strain typing was conducted using pulsed field gel electrophoresis (PFGE) as described by Tenover et al., (21) using contour-clamped homogeneous electric field apparatus (CHEF DR-III; BioRad, Hercules, CA). Restriction was done with the SmaI restriction enzyme for $S$. aureus. Analysis of results was done using BioNumerics software version 6.6 (Applied Maths NV, Belgium) using the Dice coefficient and represented by unweighted pair group method with arithmetic mean (UPGMA) with optimization settings and position tolerance set at $0.5 \%$ and $1 \%$ respectively was used to analyze the electrophoretic patterns. Clusters were defined as described by Tenover et al., (21).

\section{Results:}

Overall, fifty-eight (63.7\%) isolates were putatively methicillin resistant as detected by the phenotypic cefoxitin screen test and oxacillin MICs. The detailed phenotypic and genotypic profiles of MRSA isolates are available in the supplementary material. Thirty-five $(60.3 \%)$ isolates were from blood, 5 $(8.6 \%)$ from urethral swabs, 4 (6.9\%) from urine and 14 (24.1\%) from unknown sources.

Table 2 delineates the percentage resistance to different antibiotics tested. Generally, $37.9 \%$ of MRSA isolates displayed resistance to tetracycline, $19 \%$ to trimethoprim-sulphamethoxazole, $15.5 \%$ to clindamycin, $12.1 \%$ to gentamicin, $13.8 \%$ to ciprofloxacin and erythromycin, $6.9 \%$ to moxifloxacin and $7.0 \%$ to rifampicin. None of the MRSA isolates tested positive for inducible clindamycin resistance. All isolates were fully susceptible to linezolid, teicoplanin, vancomycin, tigecycline and fusidic acid.

Table 3 shows the distribution of resistance and virulence genes screened. The prevalence of resistance (mecA, blaz, $\operatorname{aac}\left(6^{\prime}\right)-\operatorname{aph}\left(2^{\prime \prime}\right)$, tetK and ermC) and virulence (hla and lukS/F-PV) genes respectively were $74 \%, 33 \%, 22 \%, 19 \%$, 
$3 \%, 5 \%$ and $3 \%$, with isolates organized into two highly related clades. None of the isolates expressed the h/d and eta virulence genes (Fig 1).

Table 2: Antibiotic susceptibility profile of MRSA isolates $(n=58)$

\begin{tabular}{cccc}
\hline Antibiotic & No sensitive (\%) & No intermediate (\%) & No resistant (\%) \\
& & & \\
\hline Oxacillin & $0(0.0)$ & $0(0.0)$ & $58(100.0)$ \\
Gentamicin & $49(84.5)$ & $2(3.4)$ & $7(12.1)$ \\
Ciprofloxacin & $49(84.5)$ & $1(1.7)$ & $8(13.8)$ \\
Moxifloxacin & $54(93.1)$ & $0(0.0)$ & $4(6.9)$ \\
Erythromycin & $49(84.5)$ & $1(1.7)$ & $8(13.8)$ \\
Clindamycin & $18(31.0)$ & $31(53.4)$ & $9(15.5)$ \\
Linezolid & $58(100.0)$ & $0(0.0)$ & $0(0.0)$ \\
Teicoplanin & $58(100.0)$ & $0(0.0)$ & $0(0.0)$ \\
Vancomycin & $58(100.0)$ & $0(0.0)$ & $0(0.0)$ \\
Tetracycline & $36(62.1)$ & $0(0.0)$ & $0(0.0)$ \\
Tigecycline & $58(100.0)$ & $0(0.0)$ & $0(0.0)$ \\
Fusidic acid* & $15(26.3)$ & $42(73.7)$ & $4(7.0)$ \\
Rifampicin* & $37(65.0)$ & $16(28.0)$ & $11(19.0)$ \\
\hline Trimethoprim/sulphamethoxazole & $46(79.3)$ & $1(1.7)$ &
\end{tabular}

$*_{n}=57$ as MICs could not be determined for 1 isolate each

Table 3: Distribution of virulence and resistance genes (\%) in MRSA strains

\begin{tabular}{|c|c|}
\hline Gene & $\%$ \\
\hline MecA & 74 \\
\hline$B / a Z$ & 33 \\
\hline ErmC & 3 \\
\hline $\operatorname{aac}\left(6^{\prime}\right)-\operatorname{aph}\left(2^{\prime \prime}\right)$ & 22 \\
\hline TetK & 19 \\
\hline Hla & 5 \\
\hline HId & O \\
\hline Eta & $\mathrm{O}$ \\
\hline IUKS/F-PV & 3 \\
\hline
\end{tabular}




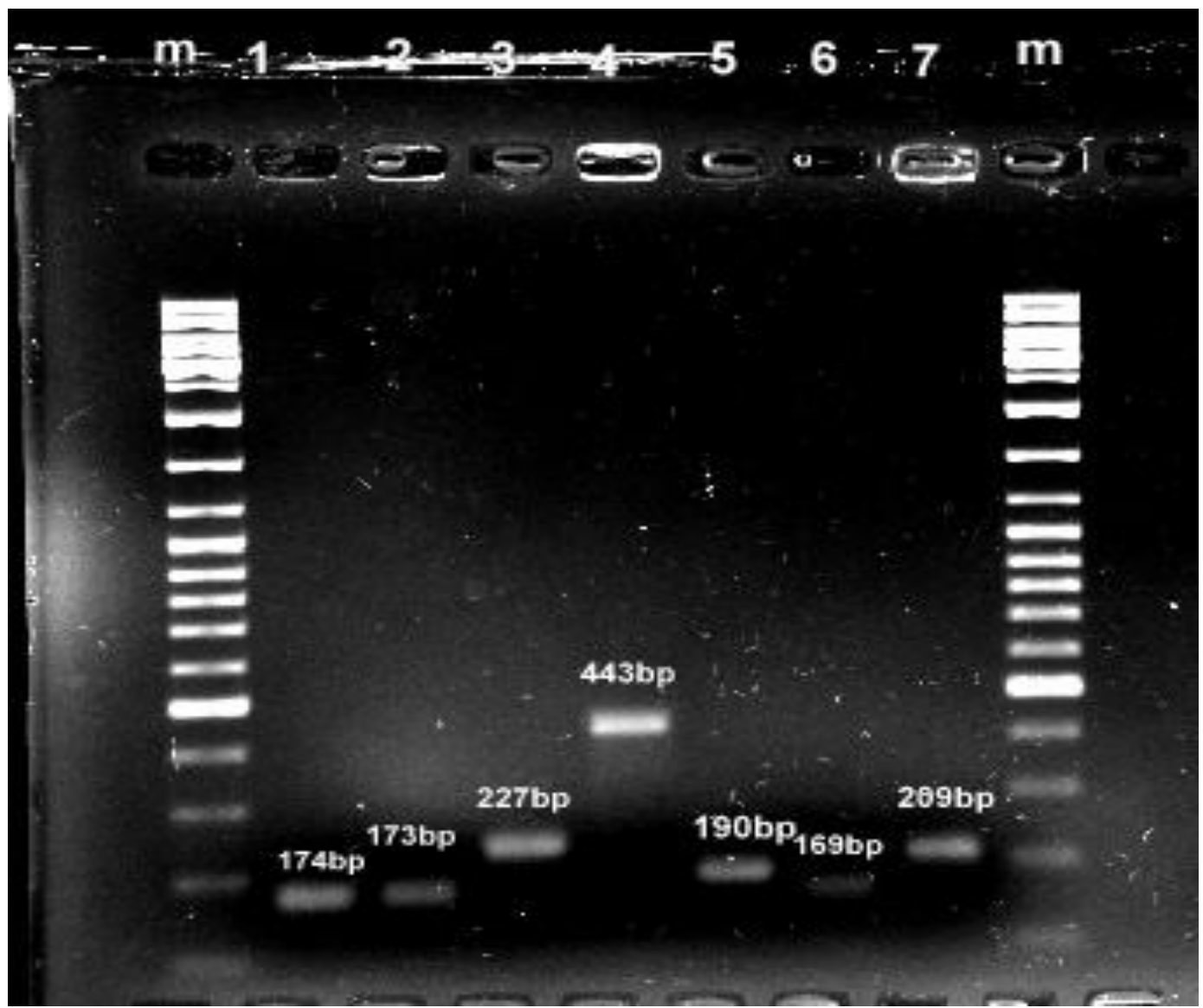

Fig 1: PCR mapping

Lanes M: DNA molecular marker, Lane 1: mecA, Lane 2: blaZ, Lane 3: $\operatorname{aac}\left(6^{\prime}\right)-a p h\left(2^{\prime \prime}\right)$, Lane 4: lukS/F-PV, Lane 5: ermC, Lane 6: tetK, Lane 7: hla

Three single nucleotide polymorphisms (SNPs) were observed for isolate S15, in the hla gene $(\mathrm{C} \rightarrow \mathrm{T}$ [12], $\mathrm{T} \rightarrow \mathrm{A}$ [15] and $\mathrm{T} \rightarrow \mathrm{C}$ [204]) as well as an insertion of $G$ [8] and an SNP $(G \rightarrow C$ [429]) in the lukS/F-PV gene (KY056259). A missense mutation of N41S was observed in the hla protein (compared with the hla protein of $S$. aureus $\mathrm{gb|AIG51324.1)}$ Two SNPs ( $\rightarrow$ A [10] and $A \rightarrow C[111])$ were also observed in the blaZ gene for isolate S31. A missense mutation of N98T was present in the blaZ protein (compared with the blaZ protein of S. aureus gb|ACP40660.1). Two putatively novel nucleotide sequences for hla and blaZ genes were submitted to GenBank and the following accession numbers were assigned; KY056259 (hla) and KY056260 (blaZ). Detailed report of sequence analysis can be found in supplementary material at www.afrjcem.org

PFGE analysis showed two major clades ( $A$ and $B$ ) of highly related isolates. The most resistant isolates against the most commonly prescribed antibiotics (i.e. gentamicin, ciprofloxacin, erythromycin, clindamycin, tetracycline and trimethoprim-sulfamethoxazole) belonged to clade B type (Fig 2). 


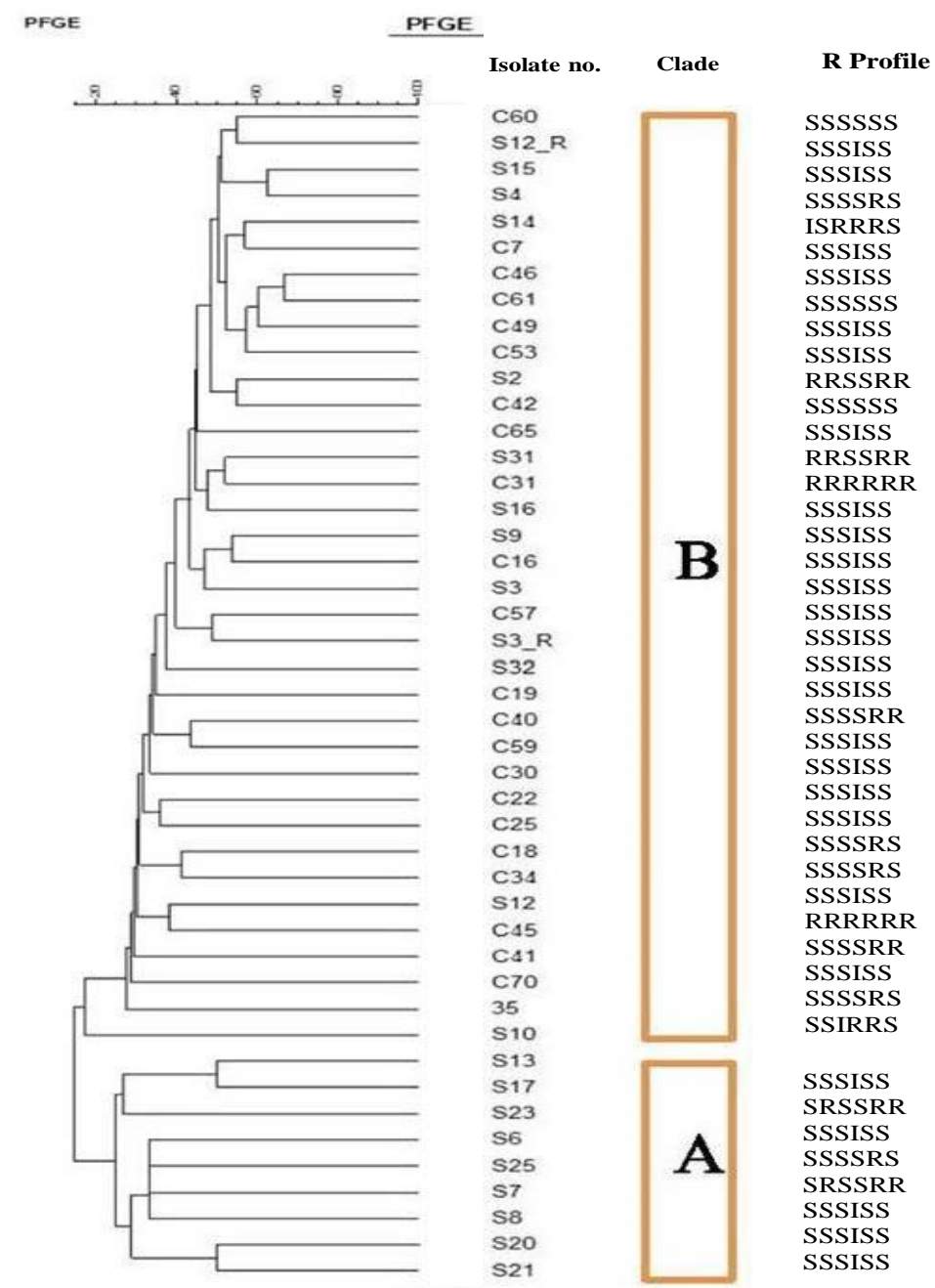

Fig 2: PFGE SmaI genotypic types generated from clinical MRSA isolates

The S, I and R (susceptible, intermediate and resistant) indicate resistance or susceptibility to gentamicin, ciprofloxacin, erythromycin, clindamycin, tetracycline and trimethoprim/sulfamethoxazole respectively

\section{Discussion:}

This study reports on the prevalence of MRSA from a Ghanaian hospital, with $58(63 \%)$ of the 91 S. aureus isolates phenotypically methicillin or oxacillin resistant, and 43 (74\%) were genotypically confirmed as MRSA. This figure is relatively high compared to the prevalence of $5.7 \%$ (11) in a Ghana study. However studies in Ethiopia, Egypt and Algeria showed an MRSA prevalence of $55.0 \%, 52.0 \%$ and $45.0 \%$ respectively in clinical isolates (22).

The use of tetracycline is common in Ghanaian communities, based on anecdotal evidence and may be obtained over-the-counter, which may partly explain the high resistance to this antibiotic. The resistance level to trimethoprim-sulphamethoxazole was lower in this study compared to resistance levels found in studies in Nigeria (90.9\%) (9), Tanzania (50.0\%) (23), and Ghana (58.3\%) (24). However Egyir et al in 2015 reported a low level of resistance $(7.0 \%)$ to trimethoprim-sulphamethoxazole in Ghana (25). Hence, MRSA from Ghana are likely to be susceptible to trimethoprimsulphamethoxazole than those from these other countries. None of the isolates was resistant to all antibiotics tested and the 
susceptibility of all isolates to linezolid, teicoplanin, tigecycline, fusidic acid and vancomycin shows that these drugs remain tenable alternatives in the treatment of MRSA infections in Ghana. However, the high costs and limited availability of these drugs in Ghana means treatment options for MRSA infections are still limited in Ghana.

Furthermore, the relatively high susceptibility levels of MRSA isolates to the quinolones, ciprofloxacin and moxifloxacin, erythromycin, gentamicin and trimethoprim-sulphamethoxazole indicates that these agents may be relied upon when the first line anti-MRSA antibiotics are not immediately available. Of the 58 isolates identified as MRSA by phenotypic tests (disc diffusion and MIC), $43(74.0 \%)$ carried the mecA gene. Methicillin resistance in staphylococcal strains that do not carry the mecA gene may be linked with another mechanism of methicillin resistance such as changes in affinity of penicillin-binding proteins for oxacillin (15). In addition, there are other chromosomally determined components aside $\operatorname{mec} A$ that are implicated in methicillin resistance. For example, FemA and $F e m B$, which encode proteins involved in the formation of the pentaglycine side chain of peptidoglycan, influence the methicillin resistance expression level in S. aureus (26). Again, methicillin resistance in the $m e c A$-negative isolates could be mediated by the mecC or mecB genes (27).

The frequency of tetK gene found in this study $(19.0 \%)$ is close to that reported in another study in Ghana (16.3\%) (28). Tetracycline resistance determinants are common and are usually found in multidrug resistant bacteria (19). TetK mediates resistance to tetracycline but not to minocycline, and is a more widespread tetracycline resistance gene than tet $L$ and tetO which are uncommon (29). The tetK and tet $M$ genes code for ribosomal target site alteration and/or efflux mechanism, limiting the effectiveness of the drug. The observation that some isolates were resistant and yet showed no tetK genes upon genotypic screening could be due to fact that their resistance to tetracycline may be mediated by other tetracycline resistant genes like tetM, which was not investigated in this study. Resistance to tetracycline is frequently due to the acquisition of new genes related to either conjugative plasmids or transposons (19). Some isolates were susceptible to tetracycline by phenotypic testing although they possessed the tetK gene, which suggests that the gene may be present but silent or minimally expressed in the absence of selection pressure. This assertion appears more likely given that the use of tetracycline for $S$. aureus infections in hospitals is on the decline in Ghanaian hospitals.

Of the eight isolates resistant to erythromycin and clindamycin (by phenotypic screening), only two possessed ermC gene upon molecular analysis. Resistance to erythromycin and clindamycin in the isolates that did not have ermC may be alternatively mediated by the msrA and $\operatorname{lin} A$ genes respectively. Mrs $A$ encodes an efflux pump that actively pumps macrolides from the bacterial cell before they can bind their ribosomal target site. This mechanism however does not create resistance to lincosamides (16). MsrA and linA genes were not investigated in this study.

Clindamycin may be useful even in HA-MRSA when susceptibility testing shows it has activity, given the limited options for MRSA infections in Ghana. However, one major concern regarding the use of clindamycin in MRSA infections is the possible development of resistance in the presence of macrolide inducers such as erythromycin (30). This has resulted in some clinicians avoiding or abandoning the use of clindamycin in staphylococcal infections whenever there is resistance to erythromycin. The 'D-zone' test therefore distinguishes strains with intrinsic genetic possibility of resistance from those that are fully susceptible to clindamycin. None of the isolates tested was positive for inducible clindamycin resistance. Those that did not possess the clindamycin 
resistance genes and were susceptible to clindamycin by susceptibility testing can therefore be safely reported as susceptible to clindamycin.

The prevalence of the $\operatorname{aac}\left(6^{\prime}\right)-a p h$ ( 2 ") gene found in this study was $22.0 \%$. Report of a previous study in Ghana showed a prevalence of $17.0 \%$ for this gene (25). The presence of the $\operatorname{aac}\left(6^{\prime}\right)$ $a p h\left(2^{\prime \prime}\right)$ gene in some isolates that showed no resistance to gentamicin implies the gene is not sufficiently expressed in these isolates. Again, some isolates carrying the $\operatorname{aac}\left(6^{\prime}\right)-\operatorname{aph}\left(2^{\prime \prime}\right)$ gene expressed intermediate susceptibility towards gentamicin and the borderline susceptibility in these isolates may be ascribed to the expression of this gene.

LukS/F-PV gene, detected in two $(3.0 \%)$ of the isolates is commonly associated with community-acquired MRSA (31). Genes encoding PVL, which is a cytotoxin that causes destruction of leucocytes and tissue necrosis, were not frequently encountered until recently, being produced by less than $5 \%$ of $S$. aureus strains worldwide. The frequency of PVL-positive $S$. aureus strains associated with clinical infections in England and Wales was reported to be $1.6 \%$ by Holmes et al (32), whiles a study in South Africa found it to be $0.3 \%$ (12). It is not therefore surprising that just two isolates carried the gene for PVL considering they are clinical isolates. Studies in Ghana however showed PVL prevalence rates of $17.0 \%(5 / 30)$ and $63.8 \%$ among hospital S. aureus isolates $(25,28)$. Although PVL genes are mostly associated with community strains of MRSA, data from West and Central Africa showed that no less than $40.0 \%$ of clinical methicillin susceptible $S$. aureus (MSSA) isolates in these regions are PVL-positive $(7,13)$. Thus, the acquisition of mecA gene by PVL-positive MSSA and the potential spread of PVL-positive CA-MRSA could pose a challenge in the control of infections in countries with inadequate resources in Africa. There was an insertion of $G(8)$ and an SNP $(G \rightarrow C$ [429]) in the lukS/F-PV gene.

Alpha haemolysin is encoded by hla was found in $5 \%$ of the isolates and plays an important role in staphylococcal infections (20). This is in contrast to reports from Uganda (14), United States (33) and Iran (20) where the frequency of hla recorded were $100.0 \%, 100.0 \%$ and $93.15 \%$ respectively, which suggests that the geographical distribution of this gene may be lower in Ghana. Alpha haemolysin, when secreted by $S$. aureus, integrates into host cell membranes and causes lysis of eukaryotic cells, with erythrocytes being particularly susceptible (34).

None of the isolates harbored the gene for the exfoliative toxin, eta. This is consistent with data from another study in Ghana (25). Three SNPs were observed for isolate $\mathrm{S} 15, \mathrm{viz}$, in the hla gene $(\mathrm{C} \rightarrow \mathrm{T}$ [12], $\quad T \rightarrow A$ [15] and $T \rightarrow C$ [204]). A missense mutation of N41S was observed in the hla protein (compared with the hla protein of S. aureus gb|AIG51324.1). The effects of SNPs at different positions of the codon may affect the expression and functioning of this gene. Alpha haemolysin hyperproduction in $S$. aureus is a multifactorial process affected at both the genomic and transcriptional levels (35). A study conducted by Liang et al., in 2011 identified SNPs in the hla gene at positions 2376,2483 and 2484 from the start codon, associated with alpha toxin hyperproduction (35).

The most resistant isolates against the most commonly prescribed antibiotics such as gentamicin, ciprofloxacin, erythromycin, clindamycin, tetracycline and trimethoprim-sulfamethoxazole belonged to clade B type. Detailed patient demographic data was unavailable, making the discussion of clonal relatedness as well as hospital-associated and community-acquired comparisons challenging.

\section{Conclusion :}

In conclusion, this study provides information on the occurrence of MRSA from a major referral hospital in Ghana over a 5-month period. Results indicated a fairly high occurrence of MRSA. Some 
isolates carried the mecA, blaZ, tetK, $\operatorname{aac}\left(6^{\prime}\right)-\operatorname{aph}\left(2^{\prime \prime}\right)$, ermC, lukS/F-PV and hla genes. The high occurrence of MRSA found in this study is worrying, considering that there are limited treatment options for antibiotic-resistant S. aureus in Ghana. There is an urgent need to institute effective surveillance mechanisms to monitor MRSA and implement stringent infection prevention and control programmes to forestall its spread.

\section{Conflict of interest:}

\author{
Professor Essack is a member of \\ the Global Respiratory Infection \\ Partnership (GRIP) and the Global \\ Analgesic Steering Committee sponsored \\ by unrestricted educational grants from \\ Reckitt and Benckiser.
}

\section{Acknowledgments:}

We acknowledge Noyise Ntshobeni of the Department of Microbiology, Daniel Amoako Gyamfi of the Antimicrobial Research Unit, University of KwaZulu Natal, and Dr John Osei Sekyere of the Department of Medical Microbiology, University of Pretoria, South Africa, for their technical assistance.

This study was supported by the National Research Foundation Incentive Funding for Rated Researchers Grant No.: 85595 awarded to Prof S. Y. Essack and a Masters Scholarship awarded to Jonathan Asante by the College of Health Sciences, University of KwaZulu-Natal. The funders had no role in the study design, data collection and interpretation, or the decision to submit the work for publication.

\section{References:}

1. Diekema, D. J., Pfaller, M. A., Shortridge, D., Zervos, M., and Jones, R. N. (eds). Twenty-Year Trends in Antimicrobial Susceptibilities Among Staphylococcus aureus From the SENTRY Antimicrobial Surveillance Program. Open Forum Infectious Diseases; 2019: Oxford University Press US.
2. Chambers, H. F. The changing epidemiology of Staphylococcus aureus? Emerg Infect Dis. 2001; 7: 178-182.

3. Vandenesch, F., Naimi, T., Enright, M. C., et al. Community-acquired methicillin-resistant Staphylococcus aureus carrying PantonValentine leukocidin genes: worldwide emergence. Emerg Infect Dis. 2003; 9: 978-984.

4. Moellering Jr, R. C. MRSA: the first half century. J Antimicrob Chemother. 2012; 64: 4-11.

5. Kawamura, K., Kitaoka, K., Kimura, K., et al. Spread of seb-Positive MethicillinResistant Staphylococcus aureus SCCmec Type II-ST764 Among Elderly Japanese in Nonacute Care Settings. Microb Drug Resist. 2019.

6. Voss, A., Milatovic, D., Wallrauch-Schwarz, C., Rosdahl, V., and Braveny, I. Methicillinresistant Staphylococcus aureus in Europe. Eur J Clin Microbiol Infect Dis. 1994; 13 (1): 50-55.

7. Breurec, S., Zriouil, S., Fall, C., et al. Epidemiology of methicillin-resistant Staphylococcus aureus lineages in five major African towns: emergence and spread of atypical clones. Clin Microbiol Infect. $2011 ; 17$ (2): 160-165.

8. Ghebremedhin, B., Olugbosi, M., Raji, A., et al. Emergence of a community-associated methicillin-resistant Staphylococcus aureus strain with a unique resistance profile in Southwest Nigeria. J Clin Microbiol. 2009; 47 (9): 2975-2980.

9. Shittu, A. O., Okon, K., Adesida, S., et al. Antibiotic resistance and molecular epidemiology of Staphylococcus aureus in Nigeria. BMC Microbiol. 2011;11 (1): 92.

10. Egyir, B., Guardabassi, L., Sørum, M., et al. Molecular epidemiology and antimicrobial susceptibility of clinical Staphylococcus aureus from healthcare institutions in Ghana. PLoS One. 2014; 9 (2): 1-7.

11. Egyir, B., Guardabassi, L., Nielsen, S. S., et al. Prevalence of nasal carriage and diversity of Staphylococcus aureus among inpatients and hospital staff at Korle $\mathrm{Bu}$ Teaching Hospital, Ghana. J Glob Antimicrob Resist. 2013; 1 (4): 189-193.

12. Moodley, A., Oosthuysen, W., Duse, A., Marais, E., Group SAMS. Molecular characterization of clinical methicillinresistant Staphylococcus aureus isolates in South Africa. J Clin Microbiol. 2010; 48 (12): 4608-4611.

13. Schaumburg, F., Ngoa, U. A., Kösters, K., et al. Virulence factors and genotypes of Staphylococcus aureus from infection and carriage in Gabon. Clin Microbiol Infect. 2011; 17 (10): 1507-1513.

14. Kateete, D. P., Namazzi, S., Okee, M., et al. High prevalence of methicillin resistant Staphylococcus aureus in the surgical units of Mulago hospital in Kampala, Uganda. BMC Res Notes. 2011; 4 (1): 326. 
15. Clinical and Laboratory Standards Institute. Performance Standards for antimicrobial testing; twenty-fourth informational supplement. CLSI documents M100-S24. 2014;34:68-75.

16. Lewis, J. S., and Jorgensen, J. H. Inducible clindamycin resistance in staphylococci: should clinicians and microbiologists be concerned? Clin Infect Dis. 2005; 40 (2): 280-285.

17. Martineau, F., Picard, F. J., Grenier, L., Roy, P. H., Ouellette, M., and Bergeron, M. G. Multiplex PCR assays for the detection of clinically relevant antibiotic resistance genes in staphylococci isolated from patients infected after cardiac surgery. J Antimicrob Chemother. 2000; 46 (4): 527-534.

18. Momtaz, H., Dehkordi, F. S., Rahimi, E., Asgarifar, A., and Momeni, M. Virulence genes and antimicrobial resistance profiles of Staphylococcus aureus isolated from chicken meat in Isfahan province, Iran. ] Appl Poult Res. 2013; 22 (4): 913-921.

19. Ng, L-K., Martin, I., Alfa, M., and Mulvey, M. Multiplex PCR for the detection of tetracycline resistant genes. Mol Cell Probes. 2001; 15 (4): 209-215.

20. Alfatemi, S. M. H., Motamedifar, M., Hadi, N., and Saraie, H. S. E. Analysis of virulence genes among methicillin resistant Staphylococcus aureus (MRSA) strains. Jundishapur J Microbiol. 2014; 7 (6): 1-10.

21. Tenover, F. C., Arbeit, R. D., Goering, R. V., et al. Interpreting chromosomal DNA restriction patterns produced by pulsed-field gel electrophoresis: criteria for bacterial strain typing. J Clin Microbiol. 1995; 33 (9): 2233.

22. Falagas, M. E., Karageorgopoulos, D. E., Leptidis, J., and Korbila, I. P. MRSA in Africa: filling the global map of antimicrobial resistance. PLoS One. 2013; 8 (7): e68024.

23. Moremi, N., Mshana, S. E., Kamugisha, E., et al. Predominance of methicillin resistant Staphylococcus aureus-ST88 and new ST1797 causing wound infection and abscesses. J Infect Dev Ctries. 2012; 6 (08): 620-625.

24. Odonkor, S. T., Newman, M. J, and Addo, K. $\mathrm{K}$. Prevalence and antibiotic susceptibility profile of methicillin resistant Staphylococcus aureus in Accra, Ghana. Microbiol Res. 2012; 3 (20): 84-87.

25. Egyir, B., Guardabassi, L., Monecke, S., Addo, K. K., Newman, M. J, and Larsen, A. R. Methicillin-resistant Staphylococcus aureus strains from Ghana include USA300. J Glob Antimicrob Resist. 2015; 3 (1): 2630.

26. Towner, K. J., Talbot, D. C., Curran, R., Webster, C. A., and Humphreys, H.
Development and evaluation of a PCR-based immunoassay for the rapid detection of methicillin-resistant Staphylococcus aureus. J Med Microbiol. 1998; 47 (7): 607-613.

27. Becker, K., van Alen, S., Idelevich, E. A., et al. Plasmid-encoded transferable mecBmediated methicillin resistance in Staphylococcus aureus. Emerg Infect Dis. 2018; 24 (2): 242.

28. Kpeli, G., Otchere, I. D., Lamelas, A., et al. Possible healthcare-associated transmission as a cause of secondary infection and population structure of Staphylococcus aureus isolates from two wound treatment centres in Ghana. New Microbe and New Infect. 2016; 13: 92-101.

29. Warsa, U. C., Nonoyama, M., Ida, T., et al. Detection of tet (K) and tet (M) in Staphylococcus aureus of Asian countries by the polymerase chain reaction. J Antibiot. 1996; 49 (11): 1127-1132.

30. Hodille, E., Badiou, C., Bouveyron, C., et al. Clindamycin suppresses virulence expression in inducible clindamycinresistant Staphylococcus aureus strains. Ann Clin Microbiol Antimicrob. 2018; 17 (1): 38.

31. Bell, J. M., Turnidge, J. D., and Participants, S. A. High prevalence of oxacillin-resistant Staphylococcus aureus isolates from hospitalized patients in Asia-Pacific and South Africa: results from SENTRY antimicrobial surveillance program, 19981999. Antimicrob Agents Chemother. 2002; 46 (3): 879-881.

32. Holmes, A., Ganner, M., McGuane, S., Pitt, T., Cookson, B., and Kearns, A. Staphylococcus aureus isolates carrying Panton-Valentine leucocidin genes in England and Wales: frequency, characterization, and association with clinical disease. J Clin Microbiol. 2005; 43 (5): 2384-2490.

33. Shukla, S. K., Karow, M. E., Brady, J. M., et al. Virulence genes and genotypic associations in nasal carriage, communityassociated methicillin-susceptible and methicillin-resistant USA400 Staphylococcus aureus isolates. J Clin Microbiol. 2010; 48 (10): 3582-3592.

34. Dinges, M. M., Orwin, P. M., and Schlievert, P. M. Exotoxins of Staphylococcus aureus. Clin Microbiol Rev. 2000; 13 (1): 16-34.

35. Liang, X., Hall, J. W., Yang, J., et al. Identification of single nucleotide polymorphisms associated with hyperproduction of alpha-toxin in Staphylococcus aureus. PLoS One. 2011; 6 (4): e18428. 